long period to experience very little inconvenience. It is not until ordinary atmospheric air is excluded and only acetylene admitted that symptoms gradually and slowly develop. This circumstance shows that so long as there is any oxygen in the aërial medium by which the animal is surrounded, it is the oxygen whioh is absorbed into the blood and very little acetylene. After a more lengthened exposure to acetylene than that which is necessary for coal gas the animal becomes intoxicated, it falls over on its side apparently profoundly asleep, and while all through the experiment its breathing has been somewhat short and rapid, stupor steals over the animal apparently painlessly, for there is not exhibited anything of the excitement, nervous or respiratory, which is seen in the narcosis produced bJ such poisonous vapours as bisulphide of carbon or benzole, or even in ordinary asphyxia. Where somnolence has been induced and asphyxia not pushed too far the rabbit, when removed from the bell jar and placed in ordinary atmospheric air, begins to move about in a few seconds in as lively a manner as if it had not been interfered with, there being neither weakness nor paralysis of its limbs. In a word, a few inhalations of atmospheric air are sufficient to restore to the animal all its faculties.

Should the inhalation have been pushed further and the animal have been very deeply asphyxiated, death may ensue the eyanosis hitherto observed being rapidly replaced by extreme pallor. In the minor and easily recoverable stages of asphyxia the vascular tension is still maintained, and there is no difficulty in obtaining a drop of blood for examination; but when the deeper stages are reached so extremel contracted are all the vessels that it is almost impossible to obtain even a trace of blood. When this stage has been reached recovery is difficult. It is interesting at this point to mention that when we examined the blood of rabbit at different stages of intoxication from acetylene, and especially in the deepest asphyxia, this fluid on spectroscopic examination always exhibited two well-marked bands of oxyhrmoglobin; also that unlike the blood in coal-gas poisoning, although resembling it in the cherry-red colou which it presented, it was readily reduced on the application of mmonium sulphide and gentle heat. To that extent, there fore, if the asphyxia caused by acetylene is not too profound -and under ordinary domestic circumstances it would not be pure acetylene atmosphere that would be inhaled by an individual, but one mixed with a large proportion of ordinary airthe danger to life seems to be less than it would be in coal-gas poisoning, and the prospect of recovery by removal to atmopheric air greater. Death may supervene, however, if the inhalation has been lengthened and atmospheric air excluded. A rabbit which was profoundly asphyxiated by acetylene, whose lip were extremely pale, its arteries, comparatively speaking, empty, pupil widely dilated. breathing short and irregular, and muscles completely paretic, died after removal from the bell jar, death being preceded as in næmia of the brain by opisthotonos and convulsions first of the fcre imbs, then of the hind, and subsequently the tremors became general. At the necropsy the heart felt hard to the touch, and was firmly conracted, both auricles and ventricles were filled with dark clot; th lungs were pale; the liver not unduly filled with blood; the kidnevs howed a dark venous coloration at the junction of cortex and medulla, while the vessels on the surface of the brain were pale and empty, and on section the brain tissue was extremely pale. The bladder was distended ; the urine was quite free

The rabbit died long after its removal from the acetylene ntmosphere, after it had been breathing for twenty minutes ordinary air superficially and irregularly. The condition of the heart found at the necropsy is scarcely that observed in asphyxia; some other factor, therefore, contributed to the death of the animal, a point to which I may allude in a sub. sequent communicatlon.

\title{
A CASE OF CONGENITAL HYPERTROPHY OF THE PYLORUS.
}

\section{H. D. ROLLESTON} M.D. F.R.C.P

Senior Assistant Physician to St. George's Hospital and to the Victoria

THE rarity of congenital hypertrophy of the pylorus serves as a sufficient excuse for placing the following case on record:

A male child, between 7 and 8 weeks old was recintl brought for treat ment to the Victoria Hospital for Children in a state of extreme emaciation. The previous history elicited was as follows : At birth the child was apparently healthy ; from the first, however, he vomited the breast milk. After a fortnight, owing to the inability of the mother (who had to go out to work) to nurse him any longer, he was fed by hand on condensed milk, and later on cow's milk; the vomiting, which occurred about half an hour after meals, however continued. Accompanying this there was progressive wasting and constipation of the bowels.

When the child first came under observation there was emaciation to an extreme degree, and kerato-malacia, most marked in the left eye. No tumour was felt in the region of the pylorus. Death ensued four days ater, the vomiting being rather less during the last week of life. The age of the child at death was 8 weeks. A post-mortem examination was made five days after death. The weight of the child was 4 lbs. 13 0zs., the average weight according to Galton's life-history album being $15 \mathrm{lbs}$. Nothing abnormal was noted in any of the organs excepting the stomach. The pyloric end of the viscus was at once seen to be markedly thickened t was about three quarters of an inch long, and the lumen was about the capacity of a No. 4 male catheter. The stomach was a little dilated, and ts walls were distinctly thickened in the neighbourhood of the pylorus. The duodenum was normal. The intestines generally were collapsed and emptr. No dilatation of the cesophagus was noticed.

Microscopically the mucous membrane was thrown into folds and showed some catarrh. The submucosa was much condensed. Both th muscular coats, but more especially the circular, were hypertrophied There was no small-cell infiltration or fibrosis of the muscular coats, and there seemed to be no change beyond hypertrophy.

\section{RemaRKs.}

This case is one of the group of cases of congenital hypertrophy of the pylorus, of which at least 17 have been recorded with post-mortem examination. Thomson ${ }^{1}$ has done much to establish the recognition of this disease, and Finkelstein ${ }^{2}$ has collected to cases, including 2 recorded by Herschsprung, 4 by Henschel, ${ }^{3}$ and 3 by Gran, ${ }^{4}$; other cases have been described by Thomson (3), Schwyzer (2) ${ }^{5}$ Pedden, ${ }^{6}$ Pitt, ${ }^{7}$ and De Bruyn Kops, ${ }^{8}$ while Soltau Fenwick ${ }^{9}$ briefly refers to two cases that he has seen. Thomson recognises as belonging to this class cases recorded by Williamson in 1841 and Dawosky in 1842 .

Age.-The average age in 17 cases was 5 months, but this was largely due to the inclusion of 2 cases of Henschel's, aged 16 and 24 months; excluding these 2 , the average age for the 15 cases was 3 months, the extremes being 7 months and 3 weeks. These cases, therefore, form a distinct group, and are evidently very different from $R$. Maier's ${ }^{10} 31$ cases of congenital stenosis of the pylorus, 21 of which were collected by himself and 10 by Landerer. The ages in this series varied between 12 and 80 years; the youngest were in girls aged 12 and 16 years respectively, the cases being equally distributed over the subsequent decades. These cases, which are often referred to as cases of congenital origin, are, it would seem, of a different nature from those we are now discussing and are rather allied to chronic pyloric fibrosis.

Sex.-In 15 of the cases in which the sex is recorded, 8 were females and 7 males, so that including our own case the incidence of the disease appears to fall equally on the two sexes.

Influence of Heredity.-Henschel met with 3 cases in the same family, thus showing that, like some other congenital conditions, especially congenital obliteration of the bile ducts, the lesions may repeat itself in the offispring of the same mother. There is no evidence that congenital syphilis plays a part, and though, on the view that it is a disturbance of nerve co-ordination, it might naturally be thought that the parents would be found to be nervously unstable, this is only definitely stated to be so in a small minority of cases. (Thomson, ${ }^{11}$ Schwyzer. ${ }^{12}$ ) This, among other points, requires urther investigation.

The cause of this muscular hypertrophy has been ably discussed by Thomson, who has proposed the name of "congenital gastric spasm" 13 for this condition. He believes it to be due to nervous inco-ordination, which leads to simultaneous contraction of the stomach and the pyloric sphincter, and so to overwork of both. There is no evidence of any gross cause such as ulceration, and he dismisses the suggestion, which he himself raises, of the pyloric spasm;being due to any irritating property of the liquor amnii swallowed in the later months of intranterine life by the fœetus, on the ground that there is no evidence of irritation on the mucosa. However, the mucous membrane is described in some of the recorded cases (Thomson, Pedden, Schwyzer, Finkelstein) as being inflamed, and, though this may quite conceivably be a secondary result of the spasm, it prevents this ingenious suggestion boing put entirely aside, though whether the fotus swallows the liquor 
amnii, and how much nutrition it would get out of a fluid containing only 1.9 proteid matter in 1,000 parts, ${ }^{14}$ is another question.

In adults a form of acid dyspepsia, chronic gastritis with hypersecretion of gastric juice and spasm of the pylorus, has been described, and is often called Reichmann's disease. Opinions, however, differ as to whether the pyloric obstruction is spasmodic and nervous in origin, or whether after all it is not purely mechanical. But even if the first alternative be true, the congenital condition with which we are now concerned does not appear to be exactly analogous to it, for Fenwick, in one of his cases, found the amount of $\mathrm{HCl}$ in the gastric juice normal, and Gran, in one of his cases, found that it was diminished.

\section{REFERENCES.}

1 Edinburgh Hospital Reports, vol. iv (two cases); Scottish Medical and Surgical Journal. June. 897 (one case). 2 Jahrb. f. Kinderheilk., Bd xliii, s. 105, 1896. ${ }^{3}$ Archiv f. Kinderheilk., Bd. xiii, s. 32, 1891. 4 Jahr. f. Kinderheilk., Bd. xli, s. 118. SNew York Medical Journal, vol. lxiv, p. 674 : vol. Xvi, p 726. Soc. London, vol. XIli, p. 63, 1892. Q Quoted in EPITOME, RRITISH MRDICAL JOURAL, 1897, vol. 1 par. 103. ren, 1897, p. 315. 10 Virchow's Archiv, Bd. 102, s. 413. 11 Edinburgh Hospital hedical and Sirgical Nournal, June cal Physiology and Pathology, $80 \mathrm{~g}, \mathrm{p} .355$.

\section{MEMOR A NDA: \\ MEDICAL, SURGICAL, OBSTETRICAL, THERA- PEUTICAL, PATHOLOGICAL, ETc.}

URAMIC ECLAMPSIA : COMA : RECOVERY. ON March 8th I was called to see a primipara, aged 24, and arrived about 3 P.M. The patient was cold and collapsed, pulse weak and rapid (about i4o per minute); she had a deathlike pallor, as though she had suffered from severe hæmorrhage; her face and legs were very cdematous, and she was quite unconscious. The mother stated that the patient had, about an hour before my arrival, been delivered of a stillborn child, and had been attended by a midwife. She did not expect to be confined for about another two months, and the appearance of the child bore out this statement. About I0.30 A.M. she had a violent "fit," which lasted for about ten minutes, and this was followed in an hour by $n$ second one. She was confined at 2 P.M. had a third convulsion about two hours later, and continued to have them at intervals of from one to two hours until 2 A M. (that is, twelve hours after confinement). Since then she had been free from an attack. She had ten fits in all, two before confinement and eight after.

The patient then lapsed into a state of coma, and was totally unconscious for about thirty-six hours, after which she rallied sufficiently to take some milk and brandy.

She then remained in a state of semi-consciousness until March I 3 th (four days after confinement), taking no notice of anyone, but took medicine and nourishment when put to her lips.

On my arrival I injected pilocarpin gr.1 , after which she perspired freely. On the third day, the following powder was given : Calomel gr.iij, jalapine gr.iij, and her bowels were well opened. After this I gave her a diuretic mixture. Since then all the odema has disappeared, and her legs have assumed their normal shape. The urine had been very scanty for thirteen weeks, and was found on examination to be highly albuminous.

Now (March 23rd) there is only a slight trace of albumen. She is passing about a normal quantity of urine, and is convalescent.

Kingswinford.

ARNOLD J. THOMSON M.R.C.S.Eng., L.R.C.P.Lond.

A CASE OF STRAMONIUM POISONING.

ON January 9 th at noon Mrs. H., aged 53, took a teaspoonful of ar antiasthmatical powder in mistake for liquorice powder. At 12.45 P.M., when sitting down to dinner, she could not understand a dry feeling in her mouth, which sipping water did not affect in the least; at the same time her sight became blurred, and she experienced a peculiar sensation of swelling iis her eyes; lifting the glass to moisten her lips she exclaimed at the weight of it, and feeling herself getting worse she told her husband to go for the doctor, and from this time remembered nothing till about 6 or 7 P.M. When I saw her at 2 P.M. her condition bore a remarkable resemblance to a case of delirium tremens ; her face, however, which was markedly pale, was not expressive of suspicion or anxiety, nor was there any clammy perspiration, the skin being $p+r$ fectly dry. Her eyes were bright and staring, the pupils dilated but not excessively, and absolutely insensible to light. The flow of ideas was very rapid, and her speech so fast that only at times could any sense be made of what she said. Mirthful delirium and hallucinations were very prominent, but illusions and delusions were markedly absent. Although she often attempted to rise she seemed unable to do so from inco-ordination of the lower extremities. Sensation, however, was perfect. 'The power of swallowing at tirst seemed absent, but if she was prevented from returning what was placed in ner mouth she swallowed it. Breathing was quiet, but the pulse was very rapid, thready, and compressible. After using the stomach pump freely nitrite of ampl and digitalin (hypodermic) was administered, and shortly afterwards pilccarpin ( $\frac{1}{3}$ gr.). Recovery after the use of the latter was remarkably rapid.

Cradley Heath, Staffordshire.

B. Henry Shaw, M.B., B.Ch., B.A.O.(R.U.I.).

DISLOCATION OF UNGUAL PHALANX.

A CASE of this form of dislocation came under my care a few weeks ago. A negro female was struck with a stick, and in trying to ward off the blow her left hand came in contact with the stick, the ungual phalanx of the middle finger being dislocated forwards. I saw the case a few minutes after the occurrence; reduction was easily effected.

Linstead, Jamaica, W.I. J. Huntly-Peck, L.R.C.P.E., etc.

\section{ULCERATIVE ENDOCARDITIS TREATED WITH} ANTISTREPTOCOCCUS SERUM.

ON December 28th 1896, I was asked to see Mrs. B., aged 42, who had been invalided some time, with the following history. She had suffered from rheumatic fever the previous May, when she was laid up for eleven weeks. She had influenza previously with frequent relapses. After rheumatic fever she went to Ramsgate for three months, when she improved, but relapsed again on returning home. She was well nourished but flabby. The temperature was $98^{\circ}$, the pulse I12, and the respirations 20. Catamenia were irregular. The urine was normal. She was quite sensible, and intelligently described her own feelings. Her temperature varied almost each hour, and generally went up to over $101^{\circ}$ at night, dropped towards morning, becoming normal about midday. There was a loud systolic murmur at the apex, and the palse ranged from 100 to 120.

She had frequent attacks, beginning with chills, followed by a hot and sweating stage. There was diarrhœe at times, and vomiting was frequent. A few days later her legs were covered with a rash resembling purpura. There was a tendency to syncope if she sat upright for any time, and thirst was constant. I inclined to the diagnosis of ulcerative endocarditis.

On January 4th, 1897, Dr. Seymour Taylor kindly saw the patient with me, and confirmed this diagnnsis, suggesting at the eame time the injection of antistrept coccus ser um. The following day ro c.cm. were injected inte the subcutineous tissue of the right thigh at 3 P.M. ; the temperature went up to $102^{\circ}$ at 8 P.M., but dropped steadily to subnormal during the night, and reached $97^{\circ}$ at 2 P.M. On January 8 th $10 \mathrm{c} \mathrm{cm}$. were further injected into the right loin ; the temperature did not rise beyond $101^{\circ}$ the same night, the pulse still keeping 120.

Previous to this the patient had for some days assumed 9 heavy lethargic appearance. She was more helpless, and only answered when pressed for a reply. The injections did not seem to influence this condition one way or the other. Her pulse kept up to 120 . She continued in this drowsy semicomatose state, doubtless due to septic trouble, with suffused heavy look, and now took her nourishment badly.

On January I 5 th I was called to see her at 6 A.M., and found her in an unconscious state dying, death being due to cerebral 